\title{
Eficácia docente no ensino da matemática $^{1}$
}

Suely da Silva Rodrigues ${ }^{a}$

\section{Resumo}

Este estudo apresenta e analisa o perfil e as características relacionadas à linguagem, estruturação, gestão da aula e interação com os alunos dos 53 professores das escolas estaduais de São Paulo considerados eficazes pelo Projeto Boas Práticas Docentes no Ensino da Matemática e que responderam ao Questionário do Professor desenvolvido exclusivamente para esta pesquisa. Além disso, apresenta-se as características socioeconômicas dos alunos, as médias de proficiência em matemática no Saresp 2011 das turmas de $7^{\circ}$ e $9^{\circ}$ ano do EF e $3^{\mathrm{a}}$ série do Ensino Médio desses professores e sua comparação com as médias das outras turmas da escola onde eles lecionam e, também, com as médias gerais do Estado na mesma edição dessa avaliação. Analisando os dados obtidos, observou-se que o fato de um professor ser eficaz em uma série ou turma não garante que ele o seja em outra. Dentre os resultados dessa pesquisa destaca-se que mesmo em um grupo pequeno e selecionado de turmas, o nível socioeconômico do professor e a gestão de classe quanto ao clima disciplinar da sala de aula fizeram diferença no desempenho dos alunos.

Palavras-chave: Prática docente. Gestão de classe. Ensino de matemática. Avaliação de desempenho.

\section{Eficácia docente}

Alguns estudos têm buscado comprovar que professores eficazes provocam impactos significativos na aprendizagem dos estudantes e que a eficácia varia de acordo com as características da qualidade docente. Neste sentido, a identificação dos componentes que o professor incorpora em sua prática que possam provocar o aumento ou a queda na aprendizagem dos alunos poderá se configurar em um valioso instrumento para auxiliar no design instrucional dos projetos de formação,

1 Este artigo é um recorte de tese de doutorado aprovada em 2014 pela PUC-Rio.

a Fundação Cesgranrio. Rio de Janeiro, Rio de Janeiro, Brasil.

Recebido em: 13 abr. 2015

Aprovado em: 08 jul 2016 
capacitação e avaliação docente e com isso, resultar em medidas que promovam a eficácia escolar.

Em artigo sobre a estabilidade das classificações dos professores de Ensino Médio (EM) em condições diferentes, Newton et al. (2010) descobriram em sua pesquisa nos Estados Unidos que as avaliações de eficácia do ensino de um professor podem variar consideravelmente a partir dos diferentes modelos estatísticos, das aulas ministradas e dos anos de experiência e concluíram que é necessário muito cuidado ao se fazer inferências sobre a eficácia dos professores com base em modelos de valor agregado, especialmente para determinar resultados que podem ter consequências graves (tais como a promoção de um ciclo para outro). Para os autores, em resumo, as características dos estudantes podem modificar drasticamente a classificação dos professores, mesmo que tais características tenham sido controladas estatisticamente nos modelos de valor agregado. E, sendo assim, professores que ensinam alunos mais desfavorecidos em um determinado curso ou série recebem avaliações de desempenho inferiores do que o mesmo professor ensinando alunos mais favorecidos em outro curso ou série. Portanto, modelos que não levam em conta as características demográficas dos estudantes poderiam prejudicar professores que atendem a um grande número de alunos de baixa renda, com habilidades limitadas em inglês, como os imigrantes, ou que estão em cursos considerados fracos.

Muitas pesquisas foram desenvolvidas para estudar a prática pedagógica de professores de matemática e sua eficácia. Goe (2007), em sua revisão da associação entre qualidade do professor e resultado dos alunos, concluiu que a participação em processos de certificações externas em matemática está correlacionada com os resultados em todas as séries, e particularmente na escola secundária. A autora fala que somente na sala de aula os alunos são expostos aos conceitos matemáticos e é dada a oportunidade de explorar e praticar a matemática, sendo assim muito importante que os professores sejam de fato competentes para guiar as descobertas dos alunos. Segundo ela, as pesquisas sugerem a necessidade de uma regulamentação mais rigorosa para ser professor de matemática, mas também apontam que será difícil atrair bons profissionais enquanto existirem poucos incentivos salariais para se tornar professor em oposição aos muitos incentivos salariais para seguir outras carreiras em que as habilidades matemáticas são valorizadas.

Carnoy (2009), em seu estudo comparativo entre Brasil, Chile e Cuba para compreender os melhores resultados dos alunos cubanos, fez entrevistas nas escolas, analisou livros didáticos e filmou aulas de matemática do $4^{\circ}$ ano da educação 
primária nos três países. O pesquisador e sua equipe observaram que na maioria das salas de aula brasileiras havia pouca interação entre o professor e os alunos, os alunos basicamente copiavam o que o professor escrevia no quadro-negro, os professores não tomavam quase nenhuma iniciativa para ligar os conceitos ao procedimento e os poucos momentos de explicação se concentravam somente na descrição do procedimento utilizado.

Em relação ao uso do livro didático, o autor coloca que existe uma lacuna significativa entre o nível da matemática prescrito pelos livros e o nível do conteúdo de fato ensinado nas aulas de matemática do $4^{\circ}$ ano no Brasil. O autor também observa que o currículo cubano não aborda tanto conteúdo quanto alguns livros didáticos no Brasil, mas que basicamente todos os alunos cubanos estudam todo o conteúdo do currículo cubano especificado, diferentemente de Brasil e Chile em que o escopo curricular varia muito de escola para escola e o que se vê nos livros didáticos dos dois países não é necessariamente uma medida do conteúdo a que os alunos serão expostos durante o ano letivo. (CARNOY, 2009).

Garnica (2008) também contribui para essa discussão ao pesquisar as concepções prévias dos professores de matemática na escolha e utilização do livro didático. Os resultados apontam que os professores escolhem intencionalmente o livro que apresenta um encadeamento linear de conteúdos e que mais se aproxima do seu próprio "ideal" ou prática cotidiana, o que, em geral, não abre espaço para a adoção de práticas alternativas, mantendo o ensino de matemática tradicional: linear e repetitivo.

Esses resultados das pesquisas apenas constatam uma triste realidade presente em muitas escolas brasileiras, senão na maioria. A carência ou dificuldade de manutenção de professores especializados é um problema que persiste há anos, da mesma forma que não é novidade a consagração da pedagogia tradicional nas salas de aula brasileiras. No entanto, também existem bons professores que são eficazes em sua tarefa de ensinar matemática e cujo estudo de suas práticas docentes pode contribuir para o desenvolvimento profissional daqueles com baixos desempenhos. A certificação do professor na disciplina pode ser importante, mas está longe de ser a única característica do perfil de um bom professor de matemática. A arte de ensinar envolve algumas sutilezas que independem do conteúdo a ser ensinado e que podem fazer muita diferença no impacto do professor sobre os alunos.

Lemov (2010) reuniu no livro Teach like a Champion 49 técnicas utilizadas por professores eficazes que, segundo ele, colocariam os alunos no caminho para as 
universidades. Esse conjunto de técnicas, conhecido como Taxonomia de Lemov, é fruto de uma pesquisa que englobou a seleção e observação das aulas dos melhores professores. Os professores foram identificados a partir dos resultados, por série e disciplina, das escolas que haviam obtido melhoria no desempenho dos alunos mais pobres nas provas padronizadas dos Estados Unidos. Para o autor, as técnicas são ferramentas necessárias, principalmente, para professores de escolas públicas lidarem com alunos nascidos na pobreza e para os quais, tão frequentemente, as janelas de oportunidades são rapidamente fechadas, o preço da falha é alto e os desafios são imensos.

As técnicas são distribuídas em sete grupos e são voltadas para a definição de altas expectativas acadêmicas, planejamento que assegure rendimento acadêmico, estruturação das aulas, envolvimento dos alunos nas aulas, criação de uma forte cultura de sala de aula, configuração e manutenção de altas expectativas comportamentais e construção da confiança. $\mathrm{O}$ autor também explicita técnicas adicionais para criar um ritmo positivo em sala de aula e para desafiar os alunos a pensar criticamente. Embora tais técnicas não tenham sido especificamente delineadas para melhorar a eficácia de professores de matemática, o estudo delas pode servir como referência para esses professores e também para pesquisas que envolvam a observação de aulas dessa disciplina.

No entanto, é preciso considerar outros aspectos desta realidade complexa. Não se pode ensinar um conteúdo que não se domina, assim como é necessário que um professor de matemática entenda as várias possibilidades de raciocínio imbricadas no entendimento ou não da matéria, nos acertos e erros dos alunos, e também saiba identificar e utilizar os recursos mais adequados para determinadas situações. A resolução de um problema, por exemplo, pode contemplar diferentes formas de se chegar a uma resposta satisfatória, da mesma forma que é preciso estar atento aos possíveis erros conceituais, lógicos ou de puro cálculo, associados a elas.

Deborah Loewenberg Ball e Heather C. Hill são duas das responsáveis pelo Learning Mathematics for Teaching (LMT), grupo de pesquisa vinculado à Universidade de Michigan e apoiado por outras instituições de ensino superior que, dentre outras atividades, elaboraram um teste formado por itens que representam algumas das competências que os professores usam no ensino da matemática elementar - representação numérica, interpretação de respostas incomuns ou algoritmos dos alunos, antecipação das dificuldades dos alunos. A elaboração do instrumento envolveu a revisão da teoria, entrevistas, observações de aulas, o estudo do currículo e dos trabalhos dos alunos e foi aplicado em professores 
engajados em um projeto de desenvolvimento profissional em matemática (HILL; SCHILLING; BALL, 2004).

A definição de Conhecimento Matemático para Ensinar (MKT - Mathematical Knowledge for Teaching) foi cunhada por Hill et al. (2008) e refere-se não apenas ao conhecimento matemático comum para indivíduos que trabalham em diversas profissões, mas também o conhecimento da disciplina que apoia o ensino, como, por exemplo, como procedimentos matemáticos específicos funcionam, como melhor definir um termo matemático para uma determinada série, e os prováveis tipos de erros que os alunos cometem em determinados conteúdos. Complementando a definição de MKT, o conceito de Qualidade da Instrução Matemática (MQI - Mathematical Quality of Instruction) engloba uma composição de diversas dimensões que caracterizam o rigor e a riqueza matemática das aulas dos professores, incluindo a presença ou ausência de erros matemáticos, explanação e justificação matemática, representação matemática, e demais relações observáveis.

Em uma das pesquisas desenvolvidas utilizando um teste baseado no MKT, Hill, Rowan e Ball (2005) correlacionaram os resultados dos professores no teste com os dos seus alunos no Comprehensive Test of Basic Skills (CBTS)/Terra Nova Mathematics Test e determinaram que resultados significativamente melhores dos alunos estavam vinculados a altos níveis de MKT dos seus respectivos professores.

O MQI é particularmente interessante, no sentido de contemplar um dos efeitos da precariedade da formação dos docentes: os erros conceituais ou matemáticos cometidos pelos professores durante as aulas. Uma das graves consequências desses equívocos é que, dessa forma, os professores induzem os alunos a aprenderem e reproduzirem tais erros.

Esses instrumentos desenvolvidos nessas pesquisas podem auxiliar no delineamento de outros estudos acerca da eficácia de professores de matemática que visem à qualificação desses profissionais para promover a melhoria da qualidade do ensino.

As várias pesquisas citadas comprovam o esforço para delinear e implementar um padrão de qualidade docente compatível com as necessidades da sociedade atual e, também, que ofereça aos alunos de diferentes níveis socioeconômicos a oportunidade de efetivamente aprender o mesmo conteúdo, com professores comprometidos com seu desenvolvimento profissional e que se sintam responsáveis pela qualidade de suas aulas. 
Essa importante tarefa tende a ser facilitada com os avanços e a disseminação das políticas de avaliação de desempenho dos alunos que, ao expor e comparar os resultados, provoca a reflexão sobre as falhas nos sistemas de ensino e incentiva a busca por soluções efetivas para a educação brasileira. $\mathrm{O}$ trabalho do professor tem sido foco de muitas críticas, mas não se pode esquecer que cabe ao governo fiscalizar e avaliar a qualidade dos cursos de formação docente e também de fornecer boas condições de trabalho, valorizar a carreira e investir em uma justa e criteriosa seleção, capacitação e avaliação dos professores da rede pública.

As pesquisas aqui citadas mergulharam na realidade da sala de aula visando encontrar e descrever indícios da eficácia docente, mas também se depararam com uma série de problemas que dificultam o processo de ensino e aprendizagem da matemática. Muitas das formulações aqui apresentadas representam ricas possibilidades para outros estudos se inspirarem em seus achados e contribuir para a produção de conhecimento neste campo. Dessa forma, os avanços nas pesquisas poderão vir a corresponder aos anseios da sociedade por um ensino de matemática de qualidade.

É justamente neste sentido que a presente pesquisa se situa. A intenção é investigar os professores eficazes, ou seja, que atingiram bons resultados na avaliação realizada pelo Estado de São Paulo em 2010. A perspectiva é contribuir com evidências sobre um aspecto pouco explorado nas pesquisas brasileiras: o que fazem os professores eficazes em sala de aula? Quais são suas práticas pedagógicas? Quais são os aspectos de gestão da sala de aula que estão presentes? Quais estão ausentes? Até que ponto esses aspectos estão associados ao perfil do professor e ao desempenho dos alunos?

O estudo utilizou os dados do Projeto Boas Práticas Docentes no Ensino da Matemática, que identificou práticas e comportamentos docentes considerados exemplares no ensino da matemática e os reuniu em um vídeo educativo que foi distribuído nas redes públicas brasileiras de Educação Básica. Maiores detalhes do projeto podem ser encontrados em Fontanive, Klein e Rodrigues (2012).

Neste sentido, este estudo, combinando perspectivas quantitativas e qualitativas, se desdobra nas seguintes perguntas: (1) Qual o perfil dos professores selecionados para participar do Projeto Boas Práticas Docentes no Ensino da Matemática? (2) Quais são as associações das características do professor com o uso do recurso didático, com diferentes estratégicas pedagógicas de gestão de classe, com o clima de sala de aula e com a interação com seus alunos? (3) Quais são as associações entre o perfil do professor com aspectos relacionados à prática de 
ensino da matemática? (4) Quais são as relações entre o perfil dos professores e as práticas docentes observadas com as médias de proficiências das turmas no SARESP$^{2}$ que eles lecionaram em 2011?

Para responder a esses questionamentos é necessário apoiar-se em uma literatura própria do campo disciplinar em que as práticas docentes são observadas. Sendo assim, as especificidades do ensino da matemática, suas relações com a escolha das atividades realizadas e atitudes incorporadas pelo professor na sala de aula são exploradas na próxima seção.

\section{A formação e a prática docente em matemática}

Ao se abordar a caracterização do conhecimento do professor, aflora a necessidade de se considerar a formação docente. Os espaços de formação são os responsáveis por capacitar os futuros professores, dotando-os de recursos pedagógicos a serem utilizados na gestão da sala de aula e, principalmente, no processo de ensino-aprendizagem. No entanto, muitos dos professores formados chegam às salas de aula sem saber lidar com as situações que se apresentam em seu cotidiano, como alunos com grande déficit de aprendizagem, desinteresse pelos estudos ou até mesmo desrespeito à figura do professor. Infelizmente, essas e muitas outras situações que prejudicam o ambiente escolar são frequentes nos dias de hoje e, portanto, afetam o trabalho docente.

Voltando-se especificamente para a formação matemática do professor, Moreira e David (2010, p. 103) expressam que

[...] entre as várias formas de desconexão do processo de formação em relação à prática, uma específica refere-se ao distanciamento existente entre os conhecimentos matemáticos trabalhados na licenciatura e as questões que se apresentam ao professor em sua ação pedagógica.

Segundo os autores, a formação matemática na licenciatura adota tanto a perspectiva quanto os valores da matemática acadêmica e, ao fazer isso, desconsidera importantes questões da prática docente escolar que não se ajustam a ela, revelando a necessidade de um redimensionamento da formação matemática

O Sistema de Avaliação de Rendimento Escolar do Estado de São Paulo (Saresp) é aplicado pela Secretaria da Educação do Estado de São Paulo com a finalidade de produzir um diagnóstico da situação da escolaridade básica paulista, visando orientar os gestores do ensino no monitoramento das políticas voltadas para a melhoria da qualidade educacional (SÃO PAULO (ESTADO), 2016). 
nas licenciaturas para melhor equacionar os papéis da matemática científica e da matemática escolar nesse processo.

Essa dissociação entre a formação e a prática pode ser apontada como um problema que pode trazer graves consequências ao desenvolvimento profissional dos professores e à aprendizagem dos alunos. O professor deveria apresentar uma base sólida tanto dos conteúdos de sua especialidade quanto de diferentes abordagens pedagógicas que propiciem a criação de um ambiente de aprendizagem significativa.

Davis et al. (2012) realizaram um estudo englobando seis Secretarias Estaduais de Educação (SEEs) e 13 Secretarias Municipais de Educação (SMEs), distribuídas nas cinco regiões brasileiras, visando identificar a configuração das modalidades e práticas empregadas na formação continuada de professores nas redes públicas de ensino. Dentre os achados da pesquisa destacam-se as críticas das SEEs e SMEs dirigidas às práticas formativas dos cursos de licenciatura. Nos depoimentos de seus representantes é salientada a ideia de que há professores que em sua formação inicial não aprenderam a dominar adequadamente os instrumentos básicos de seu trabalho e que essas lacunas desafiam o planejamento e a execução das práticas formativas de suas secretarias. Nesses depoimentos também se critica o desconhecimento das Instituições de Ensino Superior acerca da rede pública de ensino e, também, a configuração dos cursos de licenciatura no que diz respeito à articulação entre formação específica e pedagógica.

O estudo Melhores Práticas em Escolas de Ensino Médio no Brasil (INEP, 2010) mostrou após a investigação de escolas de São Paulo, Ceará, Paraná e Acre que a formação inicial e continuada de professores se apoia fortemente no trabalho individualizado e autônomo do professor e que o MEC (Ministério da Educação) e as Secretarias de Educação deveriam repensar a capacitação considerando a precariedade da formação inicial dos professores.

Essa percepção de que a formação inicial é precária ou desconectada das demandas das redes públicas poderia ser uma das respostas para a grande oferta de formações continuadas em todo o país. No entanto, para alguns dos representantes das Secretarias de Educação entrevistados na pesquisa, a formação continuada seria mais do que uma forma de minimizar as lacunas da formação inicial, teria sim um impacto maior do que a formação inicial no desenvolvimento de características profissionais, favorecendo o desenvolvimento de conhecimentos docentes e processos de socialização profissional. A formação continuada, assim, possibilitaria o desenvolvimento profissional do professor. 
Mais do que práticas docentes relacionadas ao conteúdo, também há de se dar o merecido destaque às práticas de gestão de sala de aula. Ao examinar a origem e o objetivo das demandas por formação continuada nas Secretarias de Educação, o estudo de Davis et al. (2012) também destacou o interesse das SMEs da região Sudeste em cursos sobre como "lidar com os conflitos", "como combater a violência", "como conduzir as relações étnico-raciais".

Esse interesse evidencia alguns dos desafios enfrentados pelos professores em sala de aula e que são impostos pela realidade da sociedade local. O desenvolvimento profissional implica em estar consciente do seu papel como educador, mas também engloba a necessidade de o professor buscar caminhos para se comunicar com os alunos e fazer com que eles se comuniquem entre si. Essa harmonia precisa ser alcançada para que o processo de ensino e aprendizagem tenha condições de fluir em sala de aula.

A forma como o professor gerencia a sala de aula influencia no processo de ensino e aprendizagem e, portanto, o modo como ele incentiva e organiza a comunicação entre os indivíduos, negocia os padrões de comportamento e estabelece o tempo empregado nas atividades propostas, entre outros, pode se associar positiva ou negativamente aos resultados de seus alunos.

A otimização do tempo de aprendizagem, por exemplo, contribui para que os alunos se mantenham focados nas tarefas propostas, ao mesmo tempo em que possibilita uma abrangência maior dos conteúdos prescritos para o ano escolar. Assim, a forma como se estabelece a interação e a comunicação entre alunos e professores é essencial para que a sala de aula se constitua em um ambiente com o clima propício e adequado para a implementação e manutenção de um ritmo de aprendizagem profícuo.

Nesse sentido, o clima disciplinar da sala de aula é um elemento a ser considerado e "implementar ordem e respeito suficientes para garantir o direito de todos os alunos a aprender é uma das responsabilidades do professor" (LEMOV, 2010, p. 187).

O estudo Melhores Práticas em Escolas de Ensino Médio no Brasil (INEP, 2010), indicou que uma característica recorrente das escolas selecionadas na pesquisa era a existência de normas de convivência claras, aceitas e incorporadas à dinâmica da escola. Segundo os pesquisadores, essas normas precisam ser amplamente divulgadas e legitimadas por todos da escola. Nas escolas selecionadas por eles, um aspecto muito mencionado é o de que essas normas valeriam para alunos e professores. 
Porém, a forma como essas normas são acordadas e o desrespeito ao seu cumprimento são tratados de forma a possibilitar uma variação de uma escola ou turma para outra. Muitas vezes, a própria escola estipula um padrão de comportamento que deve ser seguido por todos durante todo o tempo. Em outros casos, o professor negocia com os alunos as regras que deverão ser obedecidas em sala de aula. Esses aspectos são ressaltados pelo INEP (2010, p. 91) que afiança:

Em casos de conflito entre o previsto e o observado, procedimentos muito bem definidos são adotados e se fazem valer. No entanto, a ênfase dos códigos de conduta está em criar, manter e/ou restaurar relações interpessoais positivas, provocar o diálogo, incentivar a reflexão, construir consensos. Em outras unidades escolares, a situação é distinta, buscando-se seguir, com rigor, as consequências prescritas para subversão do código de conduta. Prepondera a assimetria nas relações, que são bastante hierarquizadas.

A postura do professor no gerenciamento do tempo de aula e na manutenção do clima disciplinar são aspectos importantes da gestão de sala de aula, mas não os únicos. Hunt (2009) sumariza, ao final de sua revisão de literatura, algumas atitudes e desempenhos do professor que estariam vinculadas à eficácia docente. Dentre elas destacam-se: que os professores eficazes respeitam seus alunos, sem se importarem com seus diferentes antecedentes, linguagem e etnia; têm grandes expectativas em relação à aprendizagem de todos os alunos; fazem uso efetivo tanto do tempo total da aula como do tempo individual de cada aluno; oferecem aos alunos oportunidades de se envolverem ativamente na sua própria aprendizagem; respondem aos erros dos alunos de uma forma positiva, que os ajude a entender e aprender o conceito tratado; desenvolvem regras para a sala de aula com os alunos e mantêm aulas seguras e ordenadas em que todos os alunos são tratados de forma justa e equitativa; e suas aulas são bem organizadas e fornecem um ambiente que promova o interesse em aprender.

Dessa maneira, a postura adotada pelo professor comunica aos alunos não só os comportamentos que ele considera aceitáveis ou o ritmo de aprendizagem desejado, mas também o modo como os professores os veem, individual e coletivamente. Se um ou mais alunos se sentem marginalizados pelo professor em sala de aula, ou percebem que o professor demonstra maiores expectativas e comprometimento com as outras turmas da escola, as interações em sala de aula serão comprometidas e, com isso, a tarefa de promover resultados positivos se tornará mais difícil. 
A forma como o professor promove as interações em sala de aula também influencia na organização das atividades de aprendizagem. $\mathrm{O}$ trabalho em grupo é uma maneira de estimular o desenvolvimento de algumas habilidades relacionadas à negociação do conhecimento e a comunicação de ideias. Ponte et al. (2007, p. 46), em investigação sobre as formas como jovens professores de matemática recém-formados e atuantes em diferentes níveis de ensino orientam a comunicação em sala de aula, apontam a importância do trabalho em grupo:

Estes (os alunos) necessitam de tempo para trabalharem juntos, para confrontarem argumentos e para negociarem a utilização de diferentes estratégias de resolução das tarefas matemáticas. É ao escrever e falar sobre a Matemática, usando a linguagem não só para expressar os seus pensamentos, mas também para partilhar significados, para compreender os argumentos dos outros alunos e do professor, que os alunos desenvolvem a sua capacidade de comunicação matemática.

Há de se ressaltar, porém, que não é somente por meio da organização do trabalho em grupos que se pode propiciar oportunidades de troca de ideias entre os alunos. $\mathrm{O}$ trabalho oral em sala de aula, seja durante a explanação do professor ou no desenvolvimento e correção das atividades propostas, pode envolver toda a turma na discussão das estratégias a serem adotadas para a resolução de uma situação-problema a partir da dúvida de um único aluno, por exemplo:

A discussão, ao pressupor uma certa igualdade de papéis, envolve os alunos (e o professor) numa partilha de significados e ideias matemáticas construídos e partilhados oralmente na sala de aula, valorizando a argumentação, quer na defesa das ideias matemáticas quer na construção de exemplos ou contraexemplos, com o objetivo de confirmar ou infirmar relações matemáticas, quer na apresentação de conjecturas e de estratégias de resolução de problemas, quer na exploração de novos caminhos. (PONTE et al., 2007, p. 47).

De maneira geral, observa-se a partir das pesquisas citadas que os aspectos aqui relacionados com a gestão de sala de aula são essenciais para o estabelecimento de um clima acadêmico favorável às aquisições dos alunos. A estruturação da aula pode ser um importante aliado na manutenção da disciplina em sala de aula, além de servir de apoio para professores inseguros quanto a seu nível de conhecimento do conteúdo. 
Segundo Lemov (2010), grandes aulas começam com o planejamento e, especificamente com o planejamento da unidade de ensino, em um processo que consiste em: refinar e aperfeiçoar o objetivo da aula com base no resultado da aula anterior; planejar uma curta avaliação diária, que vai determinar se o objetivo foi atingido; e planejar uma série de atividades que levem ao domínio do objetivo delineado.

Um bom professor deve se certificar se os alunos dispõem dos conhecimentos necessários para desenvolver a aula planejada e, assim, atingir ao objetivo estipulado inicialmente. Muitas das vezes é necessário retomar a aula anterior, a uma unidade de ensino anteriormente dada ou até mesmo a um conteúdo que deveria ter sido aprendido em séries anteriores.

Em seu trabalho sobre a gestão curricular em matemática, Ponte (2005) debate sobre os diferentes tipos de tarefas que são realizados nas salas de aula. $\mathrm{O}$ autor coloca que é necessário diversificar as tarefas, pois cada uma desempenha um papel importante para o alcance de certos objetivos curriculares. Assim, a seleção da tarefa a ser utilizada com a turma dependeria não só do objetivo do ponto de vista dos conteúdos a serem ensinados em uma sequência de aulas, mas também das habilidades matemáticas que o professor desejasse desenvolver em seus alunos durante a realização dessa atividade.

Segundo a revisão de bibliografia realizada por Bressoux (2003) sobre efeito-escola e efeito-professor, a combinação de várias práticas é mais importante que cada uma isoladamente na busca por efeitos positivos na aprendizagem dos alunos, podendo seus resultados variarem de acordo com o contexto da prática e as características de cada turma, como o nível socioeconômico, por exemplo. O autor explica:

Assim, um ensino estruturado conduz a uma maior clareza de exposição, a uma melhor compreensão dos alunos, a maiores taxas de respostas exatas pelos alunos; estes fatores contribuem para o aumento do tempo de aprendizagem efetivo, que conduz ele mesmo a menos problemas de disciplina e a mais aquisições. Estas melhores aquisições e esta melhoria de condições de ensino conduzem a menos críticas da parte do professor, a expectativas mais elevadas que o fazem adotar um ritmo mais rápido, que aumenta o conteúdo coberto durante a aula, melhora a atenção dos alunos... e assim por diante (BRESSOUX, 2003, p. 45). 
Ainda segundo o mesmo autor, dois fatores apresentam efeitos positivos de maneira constante e independentemente do contexto: o ensino estruturado e o tempo de envolvimento dos alunos em uma tarefa. Nesse sentido, para que o ensino seja bem estruturado, além de estabelecer um objetivo e selecionar as tarefas mais adequadas para atingir esse objetivo, o planejamento da aula também envolveria a escolha das ferramentas que serão utilizadas para a execução da tarefa. Embora o mais comum seja o uso de livros didáticos, apostilas, listas de exercícios ou situações-problema, os professores também podem optar pelo uso de calculadoras, computadores, vídeos, materiais concretos, áreas externas à sala de aula, jornais e revistas, entre outros. A adequação de uso desses recursos varia de acordo com o objetivo a ser alcançado e da disponibilidade e facilidade de uso do professor e dos alunos. Há também de se considerar se a atividade será desenvolvida individualmente, em dupla ou em grupos maiores.

Um dos grandes problemas enfrentados pelos professores brasileiros é a dificuldade dos alunos em compreender os textos matemáticos, principalmente os enunciados de situações-problema. Para Lemov (2010), a contextualização é a abordagem mais básica para ajudar alunos a compreenderem um texto, pois a falta de conhecimento prévio é uma das principais barreiras enfrentadas pelos alunos e afetam ainda mais os nascidos em famílias com baixo grau de instrução.

A pesquisa bibliográfica realizada por Hill et al. (2008) revela que um dos problemas encontrados nos estudos que entraram na sala de aula é o uso de metáforas inadequadas para procedimentos matemáticos. Portanto, o domínio do conteúdo e o emprego correto da linguagem matemática são imprescindíveis para o desenvolvimento de uma boa aula. Sem um sólido conhecimento matemático, o professor não consegue fazer uma contextualização correta e eficiente dos conceitos ou operações que pretende trabalhar em sala de aula.

Em estudo que buscava determinar o papel que o conhecimento matemático desempenha na qualidade do ensino da disciplina, envolvendo análises quantitativas e qualitativas, Hill et al. (2008) apontam que a riqueza da matemática, entendida aqui como o uso de múltiplas representações, ligação entre essas representações, explicação matemática e justificação, além de explicitação em torno de práticas matemáticas, tais como prova e raciocínio, e o uso de uma linguagem precisa na instrução aos alunos para transmitir claramente ideias matemáticas, são elementos-chave na prática do professor. Segundo os autores do estudo, o uso da linguagem matemática pelos professores é altamente variável e também uma característica importante da qualidade matemática em sala de aula. 
Lemov (2010) também contribui para essa discussão ao afirmar que os professores devem estabelecer e exigir um padrão de exatidão na sua aula, não se conformando com as respostas parcialmente corretas dos alunos. $\mathrm{O}$ trecho destacado a seguir ressalta a importância de o professor fazer e exigir uso do vocabulário técnico em sala de aula.

Os bons professores levam os alunos a dar respostas certas com termos comuns: "Volume é a quantidade de espaço que alguma coisa ocupa". Professores exemplares exigem o uso de vocabulário técnico preciso: "Volume é o número de unidades cúbicas de espaço ocupadas por um objeto". Esta resposta expande o vocabulário do aluno e constrói uma aprendizagem efetiva, competências que lhe serão úteis no futuro (LEMOV, 2010, p. 57).

Em outras palavras, pode-se dizer que a riqueza da matemática está relacionada com o aprofundamento dado ao estudo dos conteúdos matemáticos. Desse modo, a abordagem de um conteúdo de modo superficial nega aos alunos não só a oportunidade de aprender o necessário, mas também de entender a importância daquele conteúdo para a sua formação matemática. Nesse sentido, um professor que domina o conteúdo e emprega corretamente a linguagem matemática tem a condição inicial para abordar adequadamente, desenvolver e aprofundar o estudo das relações matemáticas envolvidas no aprendizado de seus alunos.

Estudos realizados sobre o ensino da matemática, como os publicados em 2004 e 2008 por Heather Hill e Deborah Ball, apontam a importância de o professor ajudar os alunos a construírem relações entre diferentes representações de ideias ou procedimentos. É importante que os alunos generalizem conteúdos com base em um problema particular, discutindo com os colegas e o professor como duas ou mais ideias estão relacionadas.

Em trabalho anterior, em que se analisa a relação do conhecimento matemático do professor com a matemática que ele ensina em sala de aula, Ball (1991) discute o que os professores precisam saber. Em uma tradução livre, segundo a autora, o conhecimento tácito, seja qual for o seu papel em uma atividade matemática, é inadequado para o ensino. A fim de ajudar alguém a entender e fazer matemática, ser capaz de "fazê-lo" para si mesmo não é suficiente. O nível necessário de conhecimentos para o ensino envolve ser capaz de falar sobre matemática, mas também sobre as decisões tomadas e os significados e razões para certas relações ou procedimentos e não apenas descrever os passos para seguir um algoritmo. 
Já o conhecimento explícito da matemática implica mais do que falar palavras ou fórmulas matemáticas, mas sim, deve incluir uma linguagem que vá além da superfície da representação matemática. O conhecimento explícito envolveria razões e relações, como ser capaz de explicar por que, bem como ser capaz de relacionar ideias particulares ou procedimentos para os outros dentro da matemática. Isto é mais do que "consciência metacognitiva" dos processos utilizados na resolução de um problema de matemática ou a realização de um procedimento, isso inclui a capacidade de explicar e dar forma a conceitos e procedimentos (BALL, 1991).

Ao mesmo tempo em que uma das principais condições para ser professor é dominar o conteúdo e utilizar a linguagem matemática correta e adequada ao nível da turma, um bom professor também deveria propiciar aos seus alunos oportunidades não só para expor suas ideias e validar suas hipóteses, mas também para instigar a reflexão e comunicação sobre os diferentes procedimentos que eles adotaram na resolução das tarefas matemáticas, e contribuir para o domínio e aprimoramento da linguagem matemática. Assim, o docente deveria propor situações para que os estudantes averiguem por que determinado procedimento é adequado a uma situação e não a outra e por que uma solução é ou não verdadeira.

Seria proveitoso para a formação do professor se o uso dos recursos tecnológicos em sala de aula fosse abordado tanto em sua formação inicial quanto em iniciativas de formação continuada. No caso específico dos professores de matemática, há várias ferramentas disponíveis no mercado que possibilitam não só a construção geométrica, como a modelagem matemática e a construção e o estudo de gráfico de funções, entre outros. $\mathrm{O}$ uso desses recursos seria importante na própria formação matemática dos professores e, portanto, seria necessário que os professores das licenciaturas e demais cursos superiores também fossem estimulados a adotar essas ferramentas em suas aulas. Com isso, o uso desses recursos passaria a ser habitual para os novos professores e poderia impulsionar a procura e utilização de outras ferramentas.

A discussão do uso do computador ou tablet em sala de aula também resvala na questão da iniquidade de oportunidades educacionais ocasionada pelas desigualdades sociais presentes em nosso país. Para o desenvolvimento de atividades que exijam uma postura ativa do aluno durante a interação com o computador ou tablet, muitas vezes é necessário que ele tenha o domínio das funções básicas dessa ferramenta. Com isso, entra em debate a função socializadora da escola, da qual se espera que se promova a inclusão de seus alunos no âmbito da sociedade do conhecimento.

Por sua vez, o mesmo pode ser dito em relação aos licenciandos que advêm das camadas mais pobres da população. Alguns deles podem não ter tido a oportunidade 
de ter um contato maior com o computador e os seus recursos. Ou mesmo que apresentem conhecimentos básicos, não tenham experimentado atividades que exigissem habilidades mais complexas.

A ideia de que o uso do computador aprofundaria as diferenças socioeconômicas presentes em sala de aula se perde na medida em que a promoção do uso de tecnologias oportuniza o contato e a aprendizagem dessas ferramentas, se bem planejado pelo professor e a escola ou universidade. O uso da tecnologia também pode despertar o interesse do aluno pelas atividades propostas pelo professor e servir como estímulo à aprendizagem. No entanto, o contexto da sala de aula precisa ser propício ao desenvolvimento dessa atividade.

A revisão de literatura apresentada nessas duas primeiras seções serviu de alicerce para o delineamento da metodologia empregada nesta pesquisa. A próxima seção apresenta a base de dados, os instrumentos de coleta de dados e os métodos utilizados para responder às questões de pesquisa propostas neste estudo.

\section{Metodologia}

Para responder as questões de pesquisa foi necessário desenvolver e utilizar instrumentos que estivessem embasados nos conhecimentos que vêm sendo construídos e socializados sobre a eficácia do professor e as especificidades da prática docente em matemática.

No estudo foram utilizados os seguintes instrumentos: Questionário do Professor elaborado especificamente para este estudo, Ficha de Observação, sumário das boas práticas docentes observadas por especialistas nas aulas gravadas em vídeo e as bases de dados da edição de 2011 do Saresp cedidas pela Secretaria de Estado de Educação de São Paulo (SEE-SP) com as respostas dos pais e dos alunos aos questionários socioeconômicos e de contexto, repostas dos professores de matemática da rede estadual ao Questionário do Professor e os resultados dos alunos na avaliação de matemática.

Também foi realizado o cálculo do nível socioeconômico dos alunos e dos professores, a partir das respostas ao Questionário dos Pais e dos Alunos (SARESP, 2011) e do Questionário do Professor, baseado no Critério Brasil 2008. Esse sistema de pontuação considera a posse de bens e o nível de escolaridade para determinar em qual das oito classes econômicas (A1, A2, B1, B2, C1, C2, D e E) uma pessoa ou família urbana pertence. O Quadro 1 apresenta as dimensões de análise que foram utilizadas nesta pesquisa para responder às questões de estudo. 
Os resultados que serão apresentados e analisados, resumem-se ao perfil, às práticas docentes e aos resultados das turmas no Saresp 2011 de 53 professores que responderam ao Questionário do Professor. Ao se considerar apenas as

Quadro 1. Dimensões de análise, por instrumento e questões de estudo.

\begin{tabular}{|c|c|c|}
\hline Questão de estudo & Instrumento & Dimensão de análise \\
\hline $\begin{array}{l}\text { 1. Perfil dos professores } \\
\text { do projeto }\end{array}$ & $\begin{array}{l}\text { - Questionário do } \\
\text { Professor }\end{array}$ & $\begin{array}{l}\text { Características socioeconômicas; formação } \\
\text { docente; experiência profissional; trajetória } \\
\text { docente; a relação com a escola, com os } \\
\text { alunos e seus pares; satisfação profissional; } \\
\text { expectativas dos professores para com } \\
\text { seus alunos }\end{array}$ \\
\hline $\begin{array}{l}\text { 2. Associações das } \\
\text { características do } \\
\text { professor com o uso do } \\
\text { recurso didático, com } \\
\text { diferentes estratégicas } \\
\text { pedagógicas de gestão de } \\
\text { classe, com o clima de sala } \\
\text { de aula e com a interação } \\
\text { com seus alunos }\end{array}$ & $\begin{array}{l}\text { - Ficha de } \\
\text { Observação }\end{array}$ & $\begin{array}{l}\text { Condições de sala de aula; estrutura da } \\
\text { aula; clima de sala de aula }\end{array}$ \\
\hline $\begin{array}{l}\text { 3. Associações entre o } \\
\text { perfil do professor com } \\
\text { aspectos relacionados } \\
\text { à prática de ensino da } \\
\text { matemática }\end{array}$ & $\begin{array}{l}\text { - Ficha de } \\
\text { Observação } \\
\text { - Sumário } \\
\text { do Painel de } \\
\text { Especialistas }\end{array}$ & $\begin{array}{l}\text { Estrutura da aula; as práticas docentes } \\
\text { adotadas pelos professores do projeto }\end{array}$ \\
\hline $\begin{array}{l}\text { 4. Relações entre o } \\
\text { perfil dos professores } \\
\text { e as práticas docentes } \\
\text { observadas com as } \\
\text { médias de proficiências } \\
\text { das turmas em que eles } \\
\text { lecionaram em } 2011\end{array}$ & $\begin{array}{l}\text { - Questionário do } \\
\text { Professor } \\
\text { - Sumário } \\
\text { do Painel de } \\
\text { Especialistas } \\
\text { - Bases de dados } \\
\text { do Saresp } 2011\end{array}$ & $\begin{array}{l}\text { O perfil socioeconômico dos alunos; as } \\
\text { médias do Saresp 2011; comparação } \\
\text { das médias no Saresp 2011 das turmas } \\
\text { das escolas com professores do projeto, } \\
\text { por série; a distribuição dos alunos } \\
\text { dos professores do projeto nos níveis } \\
\text { de proficiência, por série; as práticas } \\
\text { docentes adotadas pelos professores do } \\
\text { projeto; comparação das características } \\
\text { dos professores com seus pares dentro } \\
\text { da rede estadual; fatores associados ao } \\
\text { desempenho dos alunos }\end{array}$ \\
\hline
\end{tabular}

Fonte: Elaboração própria (2014). 
turmas desses professores que, em 2011, pertenciam às séries avaliadas pelo Saresp, houve a perda de um número razoável de informações, uma vez que muitas das turmas observadas eram dos dois primeiros anos do Ensino Médio. Sendo assim, a análise do desempenho dos alunos no Saresp 2011 se restringirá aos resultados de um total de 125 turmas, cuja distribuição por série está presente na Tabela 1 .

Neste trabalho utiliza-se o Modelo Linear Hierárquico ou Multinível com dois níveis interligados: aluno e turma/professor. Essa escolha advém do fato de que os alunos não são independentes, eles estão aninhados na turma que, por sua vez está diretamente relacionada ao professor. $\mathrm{O}$ procedimento de análise para as turmas de $3^{a}$ série do EM, única em que foram gerados os modelos, considerou como componentes do Modelo Básico a média do nível socioeconômico da turma menos a média das médias das turmas (MNSE), o atraso do aluno menos a média do atraso da sua turma (ATRASO), a variável SEXO do aluno (1 para sexo feminino e 0 para masculino) e a variável TURNO da turma (1 para o noturno, 0 para diurno e 0 para vespertino).

$\gamma_{i j}=\beta_{0 j}+\beta_{l j} \operatorname{ATRASO}_{i j}+\beta_{2 j} S E X O_{i j}+e_{i j}$

$\beta_{0 j}=\gamma_{00}+\gamma_{01} \mathrm{MNSE}_{j}+\gamma_{02} \mathrm{TURNO}_{j}+u_{0 j}$

$\beta_{1 \mathrm{j}}=\gamma_{10}$

$\beta_{2 \mathrm{j}}=\gamma_{20}$

onde:

- i representa o i-ésimo aluno da turma j;

Tabela 1. Número de turmas avaliadas no Saresp 2011, por série.

\begin{tabular}{lc}
\hline Série/Ano de escolaridade & Número de turmas \\
\hline $7^{\circ}$ ano do EF & 11 \\
$9^{\circ}$ ano do EF & 33 \\
$3^{\circ}$ série do EM & 81 \\
Total & 125 \\
\hline
\end{tabular}

EF: Ensino Fundamental; EM: Ensino Médio.

Fonte: Elaboração própria (2014). 
- j representa a j-ésima categoria da turma;

- $Y_{\mathrm{ij}}$ é a proficiência do aluno i na turma j;

- $\quad \beta_{\mathrm{qj}}(q=0, \ldots, 2)$ são os coeficientes do primeiro nível;

- $e_{\mathrm{qj}}$ é o efeito aleatório do modelo no primeiro nível que supõe-se ter distribuição normal de média zero e variância $\mathrm{R}$;

- $\quad \gamma_{\mathrm{qs}}(\mathrm{q}=0 ; \mathrm{s}=0,1,2)$ são os coeficientes do segundo nível;

- $u_{0 j}$ é o efeito aleatório do modelo para o intercepto $\beta_{0 j}$ no segundo nível que supõe-se ter distribuição normal de média zero e variância $\mathrm{U}_{0}$

\section{Resultados e conclusões}

O perfil delineado por meio dos dados obtidos pelo Questionário do Professor elaborado especificamente com essa finalidade diz que os professores considerados efetivos pelo Projeto Boas Práticas Docentes no Ensino da Matemática tinham, em média, 42 anos de idade, mais da metade era do sexo masculino e a grande maioria possuía uma renda razoável, se dividindo principalmente entre as classes B1 e B2. Quanto à formação acadêmica, praticamente todos eram licenciados em matemática e a grande maioria já havia concluído algum curso de pós-graduação, em maior parte nas áreas de Educação Matemática, Matemática e educação, nessa ordem.

Em relação à experiência docente e a jornada de trabalho desse grupo, a grande maioria dos professores lecionavam matemática há mais de 10 anos (Tabela 2) e pouco mais da metade trabalhava em mais de uma escola, cumprindo uma jornada

Tabela 2. Tempo de serviço lecionando matemática.

\begin{tabular}{lc}
\hline Há quantos anos você leciona matemática? & $\%$ \\
\hline De 3 a 5 anos & $3,80 \%$ \\
De 6 a 9 anos & $17,0 \%$ \\
De 10 a 15 anos & $22,6 \%$ \\
De 15 a 20 anos & $18,9 \%$ \\
Há mais de 20 anos & $37,7 \%$ \\
\hline
\end{tabular}

Fonte: Elaboração própria (2014). 
de 40 horas/aula semanais. A grande maioria dos professores mudou de escola pelo menos uma vez e, dentre os motivos dessa mudança, os mais apontados por eles estavam relacionados a ficarem mais próximos de sua residência.

A maioria dos professores atuava no Ensino Médio há mais de oito anos, segmento de ensino notadamente da preferência deles, e atuavam na escola em que foram acompanhados há pelo menos 10 anos. A maioria dos professores disse estar satisfeita com a profissão e pretendia continuar lecionando enquanto fosse fisicamente possível ou se aposentasse.

Em relação às expectativas dos professores acerca do futuro dos alunos de cada uma de suas turmas, as respostas dos professores evidenciaram que eles esperavam que a maioria dos seus alunos concluísse a Educação Básica, mas eram bastante reticentes quanto a possibilidades desses alunos entrarem na universidade ou conseguirem um bom emprego. Ainda tentou-se realizar a comparação entre as expectativas do professor com o real resultado dos alunos de suas turmas de $7^{\circ}$, $9^{\mathrm{o}}$ do Ensino Fundamental (EF) e de $3^{\mathrm{a}}$ série do EM no Saresp 2011 utilizando o percentual de alunos acima do nível de proficiência considerado Adequado, estabelecido para cada série de cada uma de suas turmas avaliadas. No entanto, os resultados não se mostraram consistentes e, portanto, não foram apresentados neste estudo.

Visando identificar as associações das características do professor com o uso de diferentes recursos didáticos e estratégias de gestão de classe foram utilizados os dados coletados por meio da Ficha de Observação, a qual foi preenchida pelos pesquisados de campo ao longo das observações in loco. Por meio desse instrumento foi possível apurar que, em geral, os professores dispunham de boas condições de infraestrutura e organização da sala de aula, que havia pouca movimentação de alunos no início e no final da aula, não causando longas esperas para o início da aula ou o encurtamento do horário efetivo de duração da aula e que a maioria das turmas observadas continham entre 26 e 40 alunos matriculados. Outro achado é que a estrutura da aula dos professores selecionados pelo projeto Boas Práticas Docentes no Ensino da Matemática não se difere muito do ensino tradicional, basicamente apoiada pelo uso da voz e do quadro negro/branco do professor e com os alunos copiando do quadro na maior parte do tempo. Mesmo assim, por mais que esses professores tenham sido os protagonistas da ação educativa em boa parte das aulas, na maioria das vezes em que a participação dos alunos ocorreu o professor esteve atento e interessado ao que o aluno dizia e, também, utilizou as ideias dos alunos para promover discussões com toda a classe. 
A identificação das associações entre o perfil do professor com sua prática de ensino se situa em uma dimensão de análise em que se torna necessário relacionar as características dos professores com as atividades que eles efetivamente conduziram em sala de aula. Por meio dos dados da Ficha de Observação e do sumário elaborado pelos integrantes do Painel de Especialistas pode-se dizer que a maioria dos professores do projeto apresentava boa oralidade e mantinha uma boa comunicação com os alunos. Eles permitiam uma ou outra intervenção dos alunos sem perder o controle da discussão vigente e, também, que os alunos compartilhassem suas ideias ou passos para resolver um problema dado, possibilitando um ambiente de mútua contribuição (Tabela 3).

Ao exigir que os alunos explicassem o procedimento que eles usaram para resolver determinado problema, que explicassem o que significava determinada resposta, ao fazer perguntas que solicitavam explicações matemáticas e que observassem os padrões encontrados, a maioria dos professores mostrou-se atenta ao desenvolvimento do raciocínio e, de certa forma, da linguagem matemática dos alunos. A boa oralidade e a boa interação com os alunos, destacadas anteriormente, além do domínio do conteúdo, são características necessárias e que facilitam o desenvolvimento dessas práticas em sala de aula.

Outras características apresentadas pelos professores e que ajudam no desenvolvimento das aulas são saber o nome dos alunos e dar tempo suficiente para eles refletirem sobre a pergunta antes de dar a resposta. Além disso, a maioria dos professores demonstrava entusiasmo com a matéria e com as ideias dos alunos, escutando com atenção as suas intervenções e estando atendo aos interesses deles, o que

Tabela 3. Postura do professor.

\begin{tabular}{lccc}
\hline $\begin{array}{l}\text { Ao trabalhar determinado conteúdo ou atividade, } \\
\text { o professor: }\end{array}$ & Sim & Não & Branco \\
\hline $\begin{array}{l}\text { É o elemento-chave, não havendo a participação dos alunos } \\
\text { na apresentação, discussão ou proposição de materiais ou } \\
\text { problemas matemáticos. }\end{array}$ & $26,8 \%$ & $71,5 \%$ & $1,7 \%$ \\
$\begin{array}{l}\text { Permite uma ou outra intervenção dos alunos, mas mantém o } \\
\text { controle do direcionamento da apresentação/discussão. }\end{array}$ & $85,4 \%$ & $12,5 \%$ & $2,2 \%$ \\
$\begin{array}{l}\text { Possibilita que os alunos compartilhem suas ideias, seus } \\
\text { diferentes raciocínios ou passos para resolver um problema } \\
\text { dado e comentem sobre as contribuições uns dos outros. }\end{array}$ & $67,1 \%$ & $29,8 \%$ & $3,2 \%$ \\
\begin{tabular}{l} 
Estimula os alunos a fazerem perguntas. \\
\hline
\end{tabular} & $69,9 \%$ & $28,6 \%$ & $1,5 \%$ \\
\hline
\end{tabular}

Fonte: Elaboração própria (2014). 
não deixa de ser um maior incentivo para a maior participação e engajamento dos mesmos nas aulas.

Embora a contextualização do conteúdo, o uso de recursos audiovisuais e de calculadoras não tenham sido muito frequentes nas aulas observadas, quando ocorreram, muitas foram citadas como práticas exemplares pelos especialistas integrantes do painel. Desse modo, os professores que apresentavam algum domínio dos recursos tecnológicos à sua disposição e não só do uso como das limitações da calculadora, conseguiram promover atividades de aprendizagem que levaram ao cumprimento dos objetivos educacionais, assim como a contextualização do conteúdo, quando realizada, alcançou as metas propostas.

A determinação das relações entre o perfil dos professores e as práticas docentes observadas com as médias de proficiências das turmas foi realizada por meio da geração e análise dos modelos estatísticos e da análise dos dados dos questionários socioeconômicos e de contexto do Saresp 2011. Como a população de respondentes da prova de matemática do Saresp 2011 é maior que a população de respondentes dos questionários socioeconômicos, as médias de proficiência, apresentadas no Quadro 2, foram recalculadas, restringindo-se somente aos alunos pertencentes aos dois grupos, ou seja, com média de proficiência em matemática e com nível socioeconômico (NSE).

No Quadro 2, observa-se que o nível socioeconômico dos alunos que estudaram com os professores do projeto, em média, não se diferencia muito da média geral de todos os alunos da rede estadual de São Paulo, nas séries consideradas. Ou seja, o melhor desempenho dos alunos dos professores acompanhados pelo estudo, não seria explicado pela desigualdade socioeconômica entre os alunos.

Quadro 2. Comparação da média geral dos alunos com NSE no Saresp 2011 com a dos alunos com NSE que estudaram com os professores do projeto, por série.

\begin{tabular}{|l|c|c|c|c|}
\hline $\begin{array}{l}\text { Ano/Série } \\
\text { Escolar }\end{array}$ & $\begin{array}{c}\text { Saresp 2011 } \\
\text { (Média PROJ } \\
\text { NSE) }\end{array}$ & $\begin{array}{c}\text { Saresp 2011 } \\
\text { (NSE PROJ) }\end{array}$ & $\begin{array}{c}\text { Saresp 2011 } \\
\text { (Média Geral } \\
\text { NSE) }\end{array}$ & $\begin{array}{c}\text { Saresp 2011 } \\
\text { (NSE Geral) }\end{array}$ \\
\hline $7^{\circ}$ do EF & 232,8 & 20,9 & 219,3 & 20,2 \\
\hline $9^{\circ}$ do EF & 263,9 & 22,6 & 248,2 & 20,8 \\
\hline $3^{a}$ do EM & 283,2 & 21,6 & 272,0 & 21,3 \\
\hline
\end{tabular}

NSE: Nível socioeconômico; EF: Ensino Fundamental; EM: Ensino Médio.

Fonte: Elaboração própria (2014). 
Analisando os resultados por turmas das três séries, observou-se que muitos professores apresentaram uma ou duas turmas com média mais alta e outras turmas com resultados não tão destacados, ou seja, o fato de um professor ser efetivo em uma série ou turma não garante que ele o seja em outra. Também se destaca, principalmente na $3^{\text {a }}$ série do EM, o fato de muitas turmas desses professores não terem sequer alcançado a média geral do Saresp. Ou seja, eles foram mais efetivos em algumas turmas do que em outras, mesmo quando o nível socioeconômico das turmas era semelhante ou até mesmo o NSE médio da turma de maior média era inferior ao da outra turma. Mesmo assim, poucos foram os casos em que as médias das turmas dos professores desse estudo foram superadas pelas médias alcançadas pelas turmas dos outros professores da mesma escola.

A maior média alcançada por uma turma do projeto foi igual a 334,1. Para situar esses resultados é preciso informar que apenas 26 do total de turmas de $3^{\mathrm{a}}$ série do EM avaliadas pelo Saresp 2011 obtiveram média igual ou superior a 334,0, somente sete turmas alcançaram média igual ou superior a 350,0 e duas turmas conseguiram média igual ou superior a 375,0 . Olhando para o quadro geral, apenas 431 turmas em todo o Estado obtiveram média igual ou superior a 300,0 pontos. Ou seja, algumas turmas do projeto estão dentre as que apresentaram os melhores resultados na avaliação de matemática promovida pelo Saresp.

Por outro lado, algumas das turmas dos professores do grupo estudado, não alcançaram a média geral do Saresp e obtiveram desempenho inferior ao de outras turmas da mesma escola. Assim, mesmo que muitos dos professores tenham se mostrado efetivos pelos critérios inicialmente estabelecidos (somente foram considerados para o estudo os professores que obtiveram média maior que 6,0 na prova de conhecimento específico em matemática em 2010 e cujas turmas alcançaram pelo menos 5 pontos acima da média geral nos anos 2008, 2009 e 2010), alguns deles não mantiveram essa efetividade no ano de 2011 e, portanto, foi possível traçar comparações entre as características e os desempenhos das turmas, seus alunos e professores dentro do próprio grupo estudado.

Os dados da Tabela 4 evidenciam a frequência com que algumas atitudes de incentivo, atenção e interesse para com o trabalho realizado pelo aluno da $3^{\mathrm{a}}$ série do EM, que não é a mesma apontada pelos alunos do $7^{\circ}$ ano, por exemplo, mas mesmo assim elas estão presentes nas aulas dos professores de matemática, principalmente nas aulas dos professores do projeto.

Segundo os alunos, em geral, os professores não costumam relacionar os conteúdos matemáticos com os das outras disciplinas, utilizar jogos ou brincadeiras nas aulas, 
Tabela 4. Frequência de atitudes ou atividades promovidas pelo professor de matemática, segundo os alunos da $3^{a}$ série do Ensino Médio.

\begin{tabular}{|c|c|c|c|c|c|c|c|c|c|c|}
\hline \multirow[t]{2}{*}{ Atividades } & \multicolumn{2}{|c|}{$\begin{array}{l}\text { Em todas } \\
\text { ou quase } \\
\text { todas as } \\
\text { aulas (\%) }\end{array}$} & \multicolumn{2}{|c|}{$\begin{array}{l}\text { Em } \\
\text { algumas } \\
\text { aulas (\%) }\end{array}$} & \multicolumn{2}{|c|}{$\begin{array}{l}\text { Nunca } \\
(\%)\end{array}$} & \multicolumn{2}{|c|}{$\begin{array}{c}\text { Branco } \\
\text { (\%) }\end{array}$} & \multicolumn{2}{|c|}{$\begin{array}{l}\text { Inválido } \\
\text { (\%) }\end{array}$} \\
\hline & Proj & Total & Proj & Total & Proj & Total & Proj & Total & Proj & Total \\
\hline $\begin{array}{l}\text { Costuma aguardar } \\
\text { muito tempo até que os } \\
\text { alunos façam silêncio } \\
\text { para iniciar a aula. }\end{array}$ & 15,3 & 16,4 & 45,0 & 38,9 & 23,6 & 16,0 & 1,4 & 2,7 & 0,3 & 0,3 \\
\hline $\begin{array}{l}\text { É exigente com relação } \\
\text { ao trabalho dos alunos. } \\
\text { Incentiva os alunos }\end{array}$ & 55,1 & 40,0 & 23,1 & 25,3 & 5,4 & 5,7 & 1,8 & 3,1 & 0,2 & 0,2 \\
\hline $\begin{array}{l}\text { a melhorar o } \\
\text { desempenho. } \\
\text { É atencioso e auxilia }\end{array}$ & 57,9 & 43,7 & 20,8 & 21,1 & 4,5 & 5,8 & 2,3 & 3,4 & 0,2 & 0,2 \\
\hline $\begin{array}{l}\text { os alunos a realizar as } \\
\text { tarefas. }\end{array}$ & 56,0 & 43,1 & 22,3 & 21,8 & 4,9 & 5,8 & 2,4 & 3,4 & 0,1 & 0,2 \\
\hline $\begin{array}{l}\text { Explica a matéria até } \\
\text { que todos os alunos a } \\
\text { entendam. }\end{array}$ & 56,5 & 42,6 & 21,3 & 21,6 & 5,8 & 6,5 & 1,9 & 3,3 & 0,1 & 0,2 \\
\hline Passa a lição de casa. & 37,0 & 27,4 & 37,0 & 32,4 & 9,1 & 10,7 & 2,5 & 3,6 & 0,1 & 0,2 \\
\hline Corrige a lição de casa. & 48,9 & 36,0 & 25,5 & 24,4 & 8,6 & 9,9 & 2,4 & 3,8 & 0,2 & 0,2 \\
\hline $\begin{array}{l}\text { Mostra interesse no } \\
\text { aprendizado de todos } \\
\text { os alunos. }\end{array}$ & 54,4 & 40,3 & 23,2 & 23,8 & 5,1 & 6,3 & 2,8 & 3,6 & 0,1 & 0,2 \\
\hline $\begin{array}{l}\text { Permite aos alunos } \\
\text { participarem e } \\
\text { expressarem suas } \\
\text { opiniões. }\end{array}$ & 52,7 & 37,7 & 25,7 & 25,8 & 5,1 & 7,2 & 2,2 & 3,4 & - & 0,2 \\
\hline $\begin{array}{l}\text { Propõe atividades de } \\
\text { resolução de problemas } \\
\text { variados. }\end{array}$ & 51,0 & 36,1 & 26,8 & 27,6 & 5,5 & 7,1 & 2,1 & 3,2 & 0,2 & 0,2 \\
\hline $\begin{array}{l}\text { Relaciona conteúdos } \\
\text { de matemática às } \\
\text { situações do cotidiano. }\end{array}$ & 41,1 & 27,1 & 32,2 & 30,6 & 10,0 & 13,2 & 1,8 & 3,1 & 0,5 & 0,3 \\
\hline $\begin{array}{l}\text { Indica pesquisa em } \\
\text { livros. }\end{array}$ & 16,3 & 12,1 & 34,8 & 27,0 & 32,1 & 32,0 & 2,2 & 2,9 & 0,2 & 0,2 \\
\hline $\begin{array}{l}\text { Propõe trabalhos para } \\
\text { serem realizados em } \\
\text { grupos. }\end{array}$ & 20,2 & 18,8 & 40,1 & 34,2 & 22,4 & 18,0 & 2,4 & 2,9 & 0,5 & 0,4 \\
\hline $\begin{array}{l}\text { Utiliza jogos e } \\
\text { brincadeiras nas aulas. } \\
\text { Costuma mostrar } \\
\text { a aplicação dos }\end{array}$ & 10,8 & 7,9 & 27,0 & 18,1 & 45,3 & 45,2 & 2,2 & 2,8 & 0,4 & 0,3 \\
\hline $\begin{array}{l}\text { conteúdos estudados } \\
\text { em matemática nas } \\
\text { outras disciplinas. }\end{array}$ & 18,4 & 12,7 & 40,6 & 30,6 & 24,3 & 27,7 & 2,1 & 2,9 & 0,2 & 0,2 \\
\hline
\end{tabular}

Proj: alunos do projeto; Total: alunos de toda a rede de São Paulo.

Fonte: Elaboração própria (2014). 
propor trabalhos em grupo ou indicar pesquisas em livros. A questão do pouco uso da estratégia de trabalho em grupo e de jogos já havia sido observada em outro instrumento e, a partir dos dados acima, verifica-se que é comum a toda a rede, independentemente da série. Ressalta-se, também, que a frequência com que os professores passam dever de casa diminui conforme aumenta a escolaridade.

Outro fator que chama atenção nos dados coletados é que para apenas $16,0 \%$ do total de alunos avaliados pelo Saresp, nas três séries, nunca há atraso no início da aula devido a questões de disciplina. Embora os alunos do projeto acusem uma frequência menor de atrasos devido a essa circunstância, ele ainda está presente em aulas dos professores acompanhados pelo estudo.

Muitos dados foram coletados ao longo do trabalho em uma tentativa de mostrar uma visão mais completa do que ocorreu na sala de aula, seja a partir da perspectiva dos próprios professores e dos seus alunos, ou dos pesquisadores de campo que observaram in loco o trabalho desenvolvido em sala de aula e, também, por especialistas no ensino da matemática que selecionaram as boas práticas executadas por esses professores. Algumas das características dos professores e de suas turmas, sejam socioeconômicas ou relacionadas ao desempenho, também foram analisadas em comparação com alguma população de interesse.

Alguns desses fatores se sobressaíram aos demais e foram melhor investigados a partir da elaboração de modelos estatísticos em que se analisou quais se mostraram mais significativos para o desempenho dos alunos. A variância e o desvio padrão no nível da turma e do aluno, além do percentual de variância explicada no nível da turma de todos os modelos gerados podem ser vistas no Quadro 3. Observa-se neste quadro que a combinação de variáveis dos últimos dois modelos apresentados consegue explicar aproximadamente $60,0 \%$ da variância do desempenho as turmas dos professores do projeto. Além das variáveis que compõem o Modelo Básico, mostraram-se fortemente significativos o nível socioeconômico do professor e variáveis relacionadas à gestão da classe.

O Modelo Básico (Tabela 5) congrega as variáveis ATRASO, SEXO e TURNO, extremamente significativas e com forte impacto no desempenho, além da variável MNSE, significativa a 5\%, e com baixo impacto no resultado das turmas.

Na Tabela 6, observa-se que no modelo em que as variáveis SILÊNCIO e INDISCIPLINA (ambas baseadas nas respostas dos alunos na Tabela 4) estão juntas com a variável NSEProf (NSE do professor da turma), embora a variável SILÊNCIO e um item da variável INDISCIPLINA tenham deixado de ser 
Quadro 3. Componentes da variância e percentagem explicada pela turma nos diferentes modelos.

\begin{tabular}{|c|c|c|c|c|c|}
\hline Modelos & $\begin{array}{l}\text { Variância } \\
\text { no nível } \\
\text { da turma }\end{array}$ & $\begin{array}{l}\text { Variância } \\
\text { no nível } \\
\text { do aluno }\end{array}$ & $\begin{array}{c}\text { Desvio } \\
\text { padrão } \\
\text { no nível } \\
\text { da turma }\end{array}$ & $\begin{array}{c}\text { Desvio } \\
\text { padrão } \\
\text { no nível } \\
\text { da do } \\
\text { aluno }\end{array}$ & $\begin{array}{c}\% \text { de } \\
\text { variância } \\
\text { explicada } \\
\text { no nível } \\
\text { da turma }\end{array}$ \\
\hline Modelo base 0 & 198,3 & 1928,7 & 14,1 & 43,9 & 9,3 \\
\hline Modelo base 1 & 180,2 & 1928,7 & 13,4 & 43,9 & 8,5 \\
\hline Modelo base 2 & 169,9 & 1927,5 & 13,0 & 43,9 & 8,1 \\
\hline Modelo base 3 & 171,4 & 1894,5 & 13,1 & 43,5 & 8,3 \\
\hline Modelo base 4 & 173,4 & 1862,0 & 13,2 & 43,2 & 8,5 \\
\hline Modelo base 5 & 148,9 & 1863,0 & 12,2 & 43,2 & 7,4 \\
\hline Modelo Básico & 146,2 & 1864,5 & 12,1 & 43,2 & 7,3 \\
\hline Modelo Básico_SILÊNCIO & 127,0 & 1863,2 & 11,3 & 43,2 & 6,4 \\
\hline Modelo Básico_EXIGENTE & 128,4 & 1863,8 & 11,3 & 43,2 & 6,4 \\
\hline Modelo Básico_INCENTIVA & 133,6 & 1864,2 & 11,6 & 43,2 & 6,7 \\
\hline Modelo Básico_ATENCIOSO & 133,6 & 1863,7 & 11,6 & 43,2 & 6,7 \\
\hline Modelo Básico_EXPLICA & 128,6 & 1863,5 & 11,3 & 43,2 & 6,5 \\
\hline Modelo Básico_PASSA LIÇÃO & 126,4 & 1862,8 & 11,2 & 43,2 & 6,4 \\
\hline Modelo Básico_CORRIGE LIÇÃO & 125,1 & 1863,6 & 11,2 & 43,2 & 6,3 \\
\hline Modelo Básico_INTERESSE & 135,3 & 1864,0 & 11,6 & 43,2 & 6,8 \\
\hline Modelo Básico_PARTICIPAÇÃO & 135,6 & 1863,9 & 11,6 & 43,2 & 6,8 \\
\hline $\begin{array}{l}\text { Modelo Básico_PROBLEMAS } \\
\text { VARIADOS }\end{array}$ & 129,3 & 1864,1 & 11,4 & 43,2 & 6,5 \\
\hline Modelo Básico_COTIDIANO & 146,6 & 1864,0 & 12,1 & 43,2 & 7,3 \\
\hline Modelo Básico_APLICAÇÕES & 140,3 & 1863,8 & 11,8 & 43,2 & 7,0 \\
\hline Modelo Básico_NSEProf & 126,1 & 1866,0 & 11,2 & 43,2 & 6,3 \\
\hline Modelo Básico_FALTARESPEITO & 115,1 & 1865,6 & 10,7 & 43,2 & 5,8 \\
\hline Modelo Básico_INDISCIPLINA & 102,1 & 1864,0 & 10,1 & 43,2 & 5,2 \\
\hline $\begin{array}{l}\text { Modelo Básico_} \\
\text { RELACIONAMENTO }\end{array}$ & 141,2 & 1864,9 & 11,9 & 43,2 & 7,0 \\
\hline Modelo Básico_APOIO & 123,8 & 1865,9 & 11,1 & 43,2 & 6,2 \\
\hline $\begin{array}{l}\text { Modelo Básico_SILÊNCIO_ } \\
\text { EXIGENTE }\end{array}$ & 117,7 & 1862,7 & 10,8 & 43,2 & 5,9 \\
\hline $\begin{array}{l}\text { Modelo Básico_SILÊNCIO_ } \\
\text { INDISCIPLINA }\end{array}$ & 95,1 & 1863,3 & 9,8 & 43,2 & 4,9 \\
\hline \multicolumn{6}{|l|}{ Continua } \\
\hline
\end{tabular}




\begin{tabular}{|l|c|c|c|c|c|}
\hline \multicolumn{2}{|l|}{ Continuação } \\
\hline $\begin{array}{l}\text { Modelo Básico_SILÊNCIO__ } \\
\text { EXIGENTE_CORRIGE LIÇÃO_ } \\
\text { INDISCIPLINA_APOIO }\end{array}$ & 95,2 & 1863,6 & 9,8 & 43,2 & 4,9 \\
\hline $\begin{array}{l}\text { Modelo Básico_NSEProf } \\
\text { INDISCIPLINA }\end{array}$ & 74,7 & 1865,6 & 8,6 & 43,2 & 3,8 \\
\hline $\begin{array}{l}\text { Modelo básico_SILÊNCIO_ } \\
\text { NSEProf_INDISCIPLINA }\end{array}$ & 71,8 & 1864,8 & 8,5 & 43,2 & 3,7 \\
\hline $\begin{array}{l}\text { Modelo Básico_SILÊNCIO__ } \\
\text { EXIGENTE_CORRIGE LIÇẪO_- } \\
\text { NSEProf_INDISCIPLINA_APOIO }\end{array}$ & 72,0 & 1864,9 & 8,5 & 43,2 & 3,7 \\
\hline
\end{tabular}

Fonte: Elaboração própria (2014).

Tabela 5. Modelo Básico.

\begin{tabular}{lccccc}
\hline Variável & Coeficiente & Erro padrão & GL & Valor-T & Valor-P \\
\hline INTERCEPTO & 295,389 & 2,588 & 1693 & 114,159 & 0 \\
MNSE & 1,511 & 0,675 & 76 & 2,238 & 0,028 \\
ATRASO & $-11,462$ & 2,082 & 1693 & $-5,505$ & 0 \\
SEXO & $-12,398$ & 2,127 & 1693 & $-5,829$ & 0 \\
TURNO & $-13,493$ & 3,562 & 76 & $-3,788$ & 0 \\
\hline
\end{tabular}

MNSE: Média das médias das turmas.

Fonte: Elaboração própria (2014).

Tabela 6. Modelo Básico_SILÊNCIO_NSEProf_INDISCIPLINA.

\begin{tabular}{lccccc}
\hline Variável & Coeficiente & $\begin{array}{c}\text { Erro } \\
\text { padrão }\end{array}$ & GL & Valor-T & Valor-P \\
\hline INTERCEPTO & 255,548 & 12,41 & 1693 & 20,592 & 0 \\
MNSE & 1,830 & 0,591 & 71 & 3,096 & 0,003 \\
ATRASO & $-11,464$ & 2,083 & 1693 & $-5,505$ & 0 \\
SEXO & $-12,430$ & 2,119 & 1693 & $-5,865$ & 0 \\
TURNO & $-9,782$ & 3,093 & 71 & $-3,162$ & 0,002 \\
SILÊNCIO & $-24,666$ & 14,268 & 71 & $-1,729$ & 0,088 \\
NSEProf & 1,119 & 0,352 & 71 & 3,176 & 0,002 \\
INDISCIPLINA prejudica em parte & 11,997 & 3,171 & 71 & 3,784 & 0 \\
INDISCIPLINA não prejudica & 10,948 & 9,206 & 71 & 1,189 & 0,238 \\
INDISCIPLINA não tem nessa escola & 21,805 & 5,976 & 71 & 3,649 & 0 \\
\hline
\end{tabular}

MNSE: média das médias das turmas; NSE: Nível socioeconômico.

Fonte: Elaboração própria (2014). 
significativos, as outras variáveis se mostraram muito significativas e o percentual da variância explicada pelo nível da turma caiu para 3,7\%.

Embora o número de professores envolvidos nesse estudo seja pequeno e se tenha perdido informações a respeito de alguns deles pelo fato de não terem lecionado em turmas avaliadas pelo Saresp 2011, há de se salientar que, mesmo assim, este estudo possibilitou algumas confirmações, verificações e descobertas.

As confirmações estão relacionadas ao fato de que as turmas do noturno, com algumas exceções, apresentam resultados piores do que as dos demais turnos, que o desempenho das meninas ainda não é o mesmo que o dos meninos em matemática e que professores atenciosos, exigentes e interessados no desempenho de seus alunos conseguem superar o efeito das desigualdades socioeconômicas em sala de aula.

Verificações do impacto da trajetória docente, da experiência como professor de matemática, satisfação com a carreira docente e formação acadêmica no desempenho de seus alunos mostraram que essas características não foram significativas para o desempenho desses alunos. Talvez o fato da maioria dos professores terem pós-graduação e serem bastantes experientes, tanto considerando toda a sua carreira docente quanto o tempo de trabalho na escola em que foi acompanhado pelo estudo, tenham contribuído para anular qualquer efeito devido a essa certa homogeneidade entre tais características dos professores. Verificou-se, também, o fato do trabalho em grupo ser pouco utilizado nas salas de aula não só das turmas do grupo estudado, mas em toda rede.

Como descobertas destaca-se o da contextualização do conteúdo não se mostrar significativa para o desempenho dos alunos desse grupo. A contextualização é vista por muitos como essencial para a apropriação dos conceitos matemáticos e tal constatação, dentro do grupo estudado formado por professores inicialmente reconhecidos como efetivos, causa surpresa. Além disso, destaca-se que o nível socioeconômico pouco influenciou no desempenho dos alunos e que os aspectos relacionados à gestão de classe são importantes a ponto de ter forte impacto no desempenho desses alunos.

Voltando-se às questões de estudo inicialmente propostas, as respostas obtidas mostram que o perfil dos professores selecionados pelo Projeto Boas Práticas Docentes no Ensino da Matemática apresenta como destaques a formação acadêmica e a experiência como professores de matemática. 
Embora as características do trabalho docente desses professores não se diferenciem muito das dos demais professores de matemática da rede, observou-se que a frequência de determinados comportamentos e práticas docentes considerados positivos para a aprendizagem e que causaram impacto no desempenho dos alunos foi maior nas turmas do grupo estudado do que na rede estadual como um todo, enquanto que a frequência de comportamentos e atitudes de alunos vistos como prejudiciais à aprendizagem e que também causaram impacto no desempenho dos alunos foi menor.

Os professores desse grupo, portanto, conseguiram desenvolver mais atividades relacionadas à aprendizagem de matemática, mantendo o clima disciplinar da sala de aula, sem deixar de dar voz aos alunos e acompanhá-los com toda a atenção e interesse, explicando a matéria até que todos a entendam com maior frequência, de modo a promover um ambiente de ensino com condições de levar à qualidade com equidade.

Mesmo assim, não se pode deixar de se questionar algumas ocorrências registradas nesse estudo. Muitos professores atribuíram aos alunos algumas das dificuldades enfrentadas para promover a aprendizagem. A falta de habilidade ou aptidão e o desinteresse são apontados com grande frequência como responsáveis por essas dificuldades. A motivação para o estudo é um fator de grande importância e viu-se nos resultados apurados que o incentivo do professor para a melhora do desempenho teve impacto bastante positivo.

No entanto, a falta de aptidão ou habilidade deixa margem para alguns questionamentos. Se a falta de habilidade diz respeito às lacunas de aprendizagem relacionadas aos conteúdos dos anos anteriores, o reforço dessas habilidades por meio de um ensino diferenciado praticamente não foi observado nas aulas gravadas. Em compensação, observou-se que diante de uma resposta errada, talvez causada por essa "falta de habilidade", a maioria dos professores ofereciam condições para que o aluno chegasse à resposta correta ou utilizava o erro como fonte de nova proposta didática.

Desse modo, no caso de o aluno ter dificuldades de compreensão de um novo conteúdo pela falta de conhecimento de uma matéria anterior, levando-o ao erro, havia a possibilidade dos erros decorrentes desse desconhecimento servirem como motivação para revisar esse conteúdo e preencher as tais lacunas. Por outro lado, se essa falta de aptidão for vista como uma característica pessoal do aluno como, por exemplo, uma aversão ou dificuldade natural para aprender os 
conteúdos vinculados à disciplina, então caberiam outros estudos voltados para as habilidades não cognitivas ou sócio emocionais dos alunos.

Outra constatação que leva a novos questionamentos se refere ao fato de bons professores saírem de sala de aula para atuar nas secretarias de educação dos municípios ou do próprio Estado. Isso pode ser visto como algo positivo ou negativo? Não seria melhor mantê-los em sala de aula e, talvez, utilizá-los como referência para professores novos na escola ou com dificuldades (coaching), sem eles terem de necessariamente abandonar as salas de aula? Ou será que a participação deles nas decisões das secretarias, inclusive acerca de processos de seleção e preparação dos novos professores e avaliação dos atuantes na rede pode ser melhor para elevar a qualidade do ensino? Enfim, essas são questões que também precisariam ser respondidas por mais pesquisas.

Respondidas as quatro questões de estudo é preciso ressaltar que a impossibilidade de identificar os professores das turmas que não estavam no projeto impediu que se realizassem análises estatísticas que considerassem todos os alunos avaliados. Portanto, os modelos gerados ficaram circunscritos ao grupo de professores acompanhados pelo projeto, únicos possíveis de terem suas turmas identificadas.

Outra limitação presente desde o início desta pesquisa se refere ao pequeno número de professores e turmas considerados pelo estudo, principalmente no Ensino Fundamental, o que inclusive inviabilizou a geração de modelos estatísticos que levassem a resultados consistentes no $7^{\circ}$ e $9^{\circ}$ anos do EF. Além disso, como foi dito anteriormente, houve uma perda considerável de professores e turmas ao se restringir as análises estatísticas ao subgrupo de professores cujas turmas haviam sido avaliadas pelo Saresp 2011.

Mesmo diante dessas limitações, espera-se que os resultados dessa pesquisa contribuam para a literatura nesse campo de estudos e, principalmente, para a melhoria da qualidade do processo de ensino e aprendizagem de matemática no país. Assim sendo, procurou-se desde o início deste trabalho discutir as dificuldades para se ter em sala de aula bons professores de matemática e os caminhos apontados para superá-las. Igualmente, espera-se que a caracterização das atitudes e práticas de professores efetivos dentro de uma rede pública de ensino que dispunham das mesmas condições que os demais professores da rede, sirva como exemplo para docentes que desejam aprimorar a sua prática e também contribua para a formação de novos professores. Muitas das características apreendidas por este estudo independem da disciplina e, portanto, podem servir de inspiração para docentes de outras áreas. 
Ao mesmo tempo, seria interessante que novas pesquisas voltadas para outras disciplinas fossem realizadas, de modo a servir de apoio à formação de professores das diferentes licenciaturas.

Por fim, destaca-se que este trabalho só foi possível de ser realizado pela existência da medida de conhecimento de professores e alunos e de suas respostas a questionários socioeconômicos e de contextos vinculados às avaliações externas, evidenciando a sua importância para o desenvolvimento de mais pesquisas nos mesmos moldes. 


\section{Teaching effectiveness in mathematics}

\section{Abstract}

This study presents and analyzes the profile and characteristics related to the language, structure, class management and interaction with students of 53 teachers in state schools in São Paulo considered as effective by the Good Teaching Practices in Mathematics Project and who responded to the Teacher Questionnaire exclusively developed for this research. In addition, it presents the socioeconomic characteristics of the students, the average math proficiency in SARESP 2011 of the classes of 7th and 9th grade of Elementary School and 3rd grade of High School of these teachers and their comparison with the average of the other classes of the school where they teach, and also with general averages of the state in the same issue of this review. Analyzing the data, it was observed that the fact that a teacher is effective in a series or class does not guarantee it to be so in another. A result stands out of the general results of this research: even in a small, selected group of classes, the socioeconomic level of the teacher and the class management in terms of the disciplinary climate of the classroom made a difference in student performance.

Keywords: Teaching practice. Class management. Teaching mathematics. Performance evaluation.

\section{Efectividad de la enseñanza de las matemáticas}

\section{Resumen}

Esta investigación presenta y analiza el perfil y las características relacionadas con el lenguaje, la estructura, la gestión de la clase y la interacción con los estudiantes de 53 maestros de las escuelas estatales de São Paulo considerados eficaces por el Proyecto Buenas Prácticas Docentes en la Enseñanza de Matemáticas, y que respondieron al Cuestionario del Profesor desarrollado exclusivamente para esta investigación. Además, se presentan las características socioeconómicas de los estudiantes, el nivel de competencia promedio en matemáticas en SARESP 2011 de los $7^{\circ}$ y $9^{\circ}$ años de la escuela primaria y del $3^{\circ}$ año de la escuela secundaria de estos maestros, y su comparación con la media de otros grupos de la escuela donde estos maestros enseñan, y también, con los promedios generales del estado en la misma edición de esta evaluación. Analizando los datos obtenidos, se observó que el hecho de que un maestro sea eficaz en un año o grupo escolar no garantiza que también lo sea en otro. Entre los resultados de esta investigación, se destaca que incluso en un grupo pequeño y seleccionado de grupos escolares, el nivel socioeconómico del maestro y la gestión del grupo escolar en cuanto al clima disciplinario del aula hicieron una diferencia en el rendimiento de los estudiantes.

Palabras clave: La práctica docente. Gestión de la clase. La enseñanza de las matemáticas. Evaluación de rendimiento. 


\section{Referências}

BALL, D. L. Research on teaching mathematics: making subject matter knowledge part of the equation. In: BROPHY, J. (Ed.). Advances in research on teaching. Greenwich: JAI, 1991. v. 2, p.1-47,.

BRESSOUX, P. As pesquisas sobre o efeito escola e o efeito professor. Educação em Revista, v. 38, p. 17-88, dez. 2003.

CARNOY, M. et al. A vantagem acadêmica de Cuba: por que seus alunos vão melhor na escola. São Paulo: Ediouro, 2009.

DAVIS, C. L. F. et al. Formação continuada de professores: uma análise das modalidades e das práticas em estados e municípios brasileiros. São Paulo: Fundação Carlos Chagas, 2012. (Coleção Textos FCC, 34).

FONTANIVE, N. S.; KLEIN, R.; RODRIGUES, S. S. Boas práticas docentes no ensino da matemática. Estudos \& Pesquisas Educacionais, n. 3, p. 195-277, 2012.

GARNICA, A. V. M. Um ensaio sobre as concepções de professores de matemática: possibilidades metodológicas e um exercício de pesquisa. Educação e Pesquisa. v. 34, n. 3, p. 495-510, set./dez. 2008. doi:10.1590/S1517-97022008000300006

GOE, L. The link between teacher quality and students outcomes: a research synthesis. Washington, DC: National Comprehensive Center for Teacher Quality, 2007.

HILL, H. C. et al. Mathematical knowledge for teaching and the mathematical quality of instruction: an exploratory study. Cognition and Instruction, v. 26, n. 4, p. 430-511, Sep. 2008. doi:10.1080/07370000802177235

HILL, H. C.; ROWAN, B.; BALL, D. L. Effects of teachers' mathematical knowledge for teaching on student achievement. American Educational Research Journal, v. 42, n. 2, p. 317-406, 2005.

HILL, H. C.; SCHILLING, S.G.; BALL, D. L. Developing measures of teachers' mathematics knowledge for teaching. Elementary School Journal, v. 105, n. 1, 11-30, Sep. 2004.

HUNT, B. Efectividad del desenpeño docente: una reseña de la literatura internacional y su relevância para mejorar la educación em America Latina. Santiago: Preal, 2009. (Preal documentos, 43). Disponível em: $<$ http://www. preal.org/BibliotecaN.asp?Id_Carpeta $=64 \&$ Camino $=63 \mid$ PrealPublicaciones $/ 64$ |PREALDocumentos>. Acesso em: 1 nov. 2010. 
INSTITUTO NACIONAL DE ESTUDOS E PESQUISAS EDUCACIONAIS ANÍSIO TEIXEIRA - INEP. Melhores práticas em escolas de ensino médio no Brasil. Brasília, DF: INEP, 2010.

LEMOV, D. Teach like a champion: 49 techniques that put students on the path to college. San Francisco: Jossey-Bass, 2010.

MOREIRA, P.C.; DAVID, M. M. M. S. A formação matemática do professor: licenciatura e prática docente escolar. Belo Horizonte: Autêntica, 2010.

NEWTON, X. et al. Value-added modeling of teacher effectiveness: an exploration of stability across models and contexts. Education Policy Analysis Archives, v. 18, n. 23, 2010. doi:10.14507/epaa.v18n23.2010

PONTE, J. P. Gestão curricular em matemática. In: GRUPO DE TRABALHO DE INVESTIGAÇÃO (Ed.). O professor e o desenvolvimento curricular. Lisboa: APM, 2005. p. 11-34.

PONTE, J. P. et al. A comunicação nas praticas de jovens professores de Matemática. Revista Portuguesa de Educação, v. 20, n. 2, p. 39-74, 2007.

SÃO PAULO (ESTADO). Secretaria da Educação. SARESP permite monitorar avanços da educação básica no Estado. São Paulo: Secretaria de Educação, 2016. Disponível em: http://www.educacao.sp.gov.br/saresp. Acesso em: 3 jun. 2016.

\section{Informações da autora}

Suely da Silva Rodrigues: Doutora em Educação pela Pontifícia Universidade Católica do Rio de Janeiro - PUC-Rio. Docente da Fundação Cesgranrio. Contato: suely@cesgranrio. org.br; suely_rodrigues@yahoo.com.br 